\title{
Analysis of evaporative fraction diurnal behaviour
}

\author{
Pierre Gentine $^{\mathrm{a}}$, Dara Entekhabi ${ }^{\mathrm{a}, *}$, Abdelghani Chehbouni ${ }^{\mathrm{b}}$, \\ Gilles Boulet ${ }^{\mathrm{b}}$, Benoît Duchemin ${ }^{\mathrm{b}}$ \\ ${ }^{a}$ Department of Civil \& Environmental Engineering, Massachusetts Institute of Technology (MIT), Cambridge, MA 02139, USA \\ ${ }^{\mathrm{b}}$ Centre d'Etudes Spatiales de la Biosphère (CESBIO), 18 Avenue Edouard Belin, BPI 2801, 31401, Toulouse Cedex 9, France
}

Received 7 April 2006; received in revised form 7 October 2006; accepted 8 November 2006

\begin{abstract}
Experimental studies indicate that evaporative fraction (EF), the ratio between the latent heat flux and the available energy at the land surface, is a normalized diagnostic that is nearly constant during daytime under fair weather conditions (so-called daytime selfpreservation). This study examines this observation and investigates contributions to the variability of EF due to environmental factors (air temperature, solar incoming radiation, wind velocity, soil water content or leaf area index). It is shown here that the phase difference between soil heat flux and net radiation needs to be characterized fully in application models that invoke EF daytime self-preservation. Further conditions under which the diurnally constant EF assumption can hold are also discussed.

(C) 2006 Elsevier B.V. All rights reserved.
\end{abstract}

Keywords: Evaporation; Evapotranspiration; Soil heat flux; Diurnal; Soil moisture

\section{Introduction and motivation}

Evapotranspiration (ET) is a flux linking water, energy and carbon cycles. Flux measurement networks (as FluxNet, EuroFlux, AmeriFlux) are only available in few tens of point locations around the Globe. They are costly both to install and maintain. Moreover there is a strong heterogeneity of the fluxes over the land surface because of the inherent physical diversity of the land and vegetation properties. Therefore, the locally measured fluxes cannot be representative of a whole region of interest, nor can they be used to produce mapped estimates.

\footnotetext{
* Corresponding author. Tel.: +1 617253 9698; fax: +16172588850 .

E-mail addresses: gentine@mit.edu (P. Gentine), darae@mit.edu (D. Entekhabi), ghani@cesbio.cnes.fr (A. Chehbouni), Gilles.Boulet@cesbio.cnes.fr (G. Boulet), benoit.duchemin@cesbio.cnes.fr (B. Duchemin).
}

The only currently available way to obtain ET mapping is to rely on remote sensing data that now have both nearly continuous spatial coverage and adequate temporal sampling using constellation of satellites or geostationary platforms. It is not possible to directly measure fluxes using satellite information. In fact the remotely sensed surface state measurements such as land surface temperature (LST) are only indirectly related to the state of the land surface and the corresponding heat fluxes.

Different remote sensing-based methods have been developed to estimate ET using either empirical or physically based methods (see Caparrini et al., 2004a,b for review). Physically based methods solve the energy budget at the land surface. Land surface temperature (LST) data are assimilated in models of surface energy balance. Often diurnal self-preservation of EF, which is defined as the ratio between the latent heat flux and the available energy at the land surface $\mathrm{EF}=\lambda E /\left(R_{\mathrm{n}}-G\right)$, is used to make the retrieval problem well-posed. 
The observation that EF is often constant during daytime is based on Shuttleworth et al. (1989), Nichols and Cuenca (1993) and Crago and Brutsaert (1996). They use in situ measurements of surface energy balance components to show that EF is almost constant during the daytime hours under clear skies. EF supposedly removes available energy diurnal cycle and isolates surface control (soil and plant resistance to moisture loss) on turbulent heat flux partitioning. These controls vary on approximately daily time-scales.

In an important study Lhomme and Elguero (1999) has shown that EF is not necessarily constant during daytime especially in non-fair weather conditions. This leads to ET estimation errors, in particular in the morning and late afternoon due to the typical parabolic shape of EF. The robustness of the self-preservation of $\mathrm{EF}$ and the range of its applicability under different environmental conditions is the rationale for this study. Lhomme and Elguero (1999) is the foundation for this study and the analysis here is intended to provide additional detail. Lhomme and Elguero (1999) and this study together should provide the basis to understand the daytime self-preservation of EF and assess the limitations of its application.

In order to better understand the diurnal behaviour of $\mathrm{EF}$ and its environmental dependencies it is important to have long-term field experiment data. In this paper we use a SVAT model in conjunction with micrometeorological data in order to assess the EF temporal behaviour under diverse meteorological conditions. The dual-source (soil and vegetation) SVAT model also allows the test of the influences of vegetation cover and soil moisture on EF daytime self-preservation. This model is also used to understand the possible phase shift between the different surface fluxes, which can lead to dramatic EF under/overestimation.

The field experiment data used in this study is first presented. The SVAT model outlined in Fig. 1 is described in Appendix A. Then, the diurnal course of EF is physically explained through SVAT modeling and its consistency with Lhomme and Elguero (1999) result is discussed. The partial soil moisture and vegetation cover influences on the EF diurnal shape is further analyzed. Finally, the temporal correlations between EF and the main environmental factors are discussed and a strategy for the refinement of ET estimation using both land surface temperature and EF daytime self-preservation is forwarded.

\section{Field experiment data set}

The SVAT model (see Fig. 1 and Appendix A) was calibrated and tested on two wheat parcels and one olive

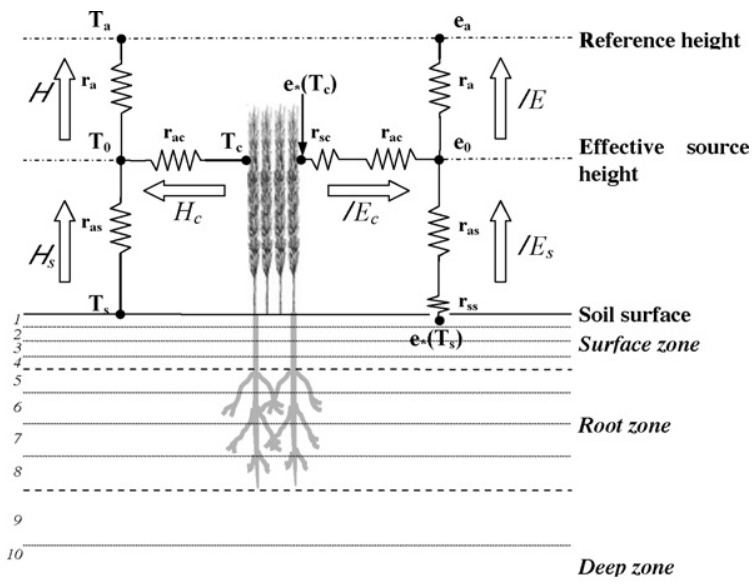

Fig. 1. Dual source (soil-canopy) resistance network. This model is coupled with a 10-layer diffusive soil model for heat and moisture transfer.

tree orchard during the 2002 and 2003 SUDMED project in the region of Marrakech, Morocco, described in further detail in Duchemin et al. (2006). The experiment area is a typical Mediterranean semi-arid region. This region is heterogeneous in terms of vegetation cover and climate both spatially and temporally. These conditions are particularly appropriate to test and apply SVAT models because of the sparse vegetation with strong phenological cycle, which permits variations in the contribution of soil and vegetation to the surface energy balance. The air temperature ranges from as low as $0{ }^{\circ} \mathrm{C}$ in the winter to $50{ }^{\circ} \mathrm{C}$ in the summer; LAI from 0 (sowing) to more than 5 before harvest.

The study site is composed of sparse vegetation (varying with season) in which latent and sensible heat fluxes are of comparable magnitude. There are both bare soil and canopy contributions to turbulent fluxes. The specific study site, named R3, is located in an irrigated area in the Haouz plain surrounding Marrakech, where wheat is the main cultivated plant.

The R3 site is a 2800 ha area where irrigated wheat is cultivated, located $45 \mathrm{~km}$ East of Marrakech. Two fields were equipped with instrumentation, namely the 123rd (R3-B123 used in this study) and 130th (R3-B130) parcels. The parcels are cultivated with wheat. The sowing date is January 13 (day of year 13). The climate is characterized by a dry and warm period with very few precipitations events in Summer and Fall. Almost all of the annual precipitation occurs in Winter and Spring (see Fig. 2). The rainy period lasts 6 months from November to April and the cumulative precipitation is generally of the order of $250 \mathrm{~mm}$ per year. The site is 

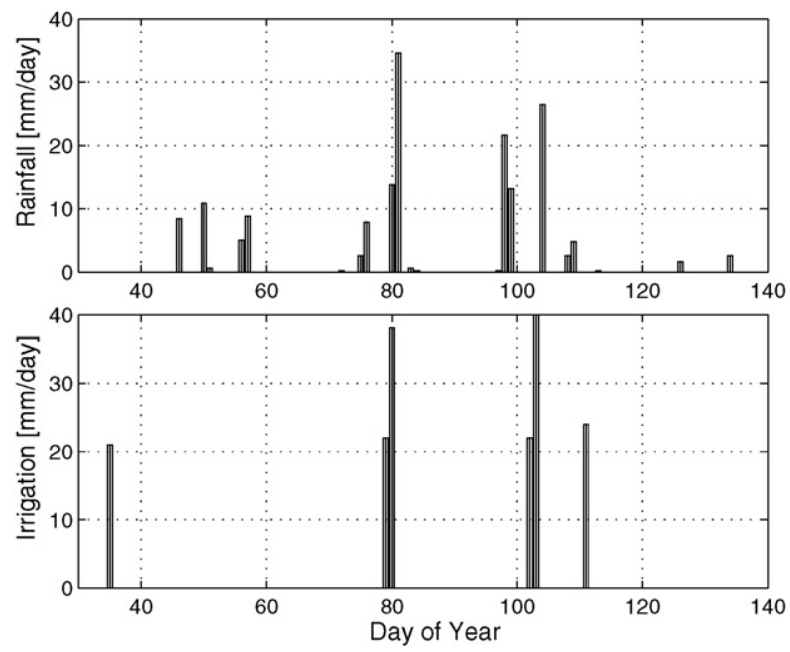

Fig. 2. Measured daily rainfall and estimated irrigation over R3 B123 in 2003 .

periodically irrigated by flooding the entire field. The parcel of interest in this study is R3-B123. Irrigation events occurred on 4 February (DOY 35), 20 March (DOY 79), April 13 (DOY 103) and 21 April (DOY 111) with a mean $25 \mathrm{~mm}$ supply each time (see Fig. 2).

Energy fluxes were continuously monitored, starting 4 February (DOY 35) and lasting the entire wheat season until 21 May (DOY 141). It covered the whole wheat cycle: sowing, vegetative growth, full canopy, and senescence. Vegetation appears around February (DOY
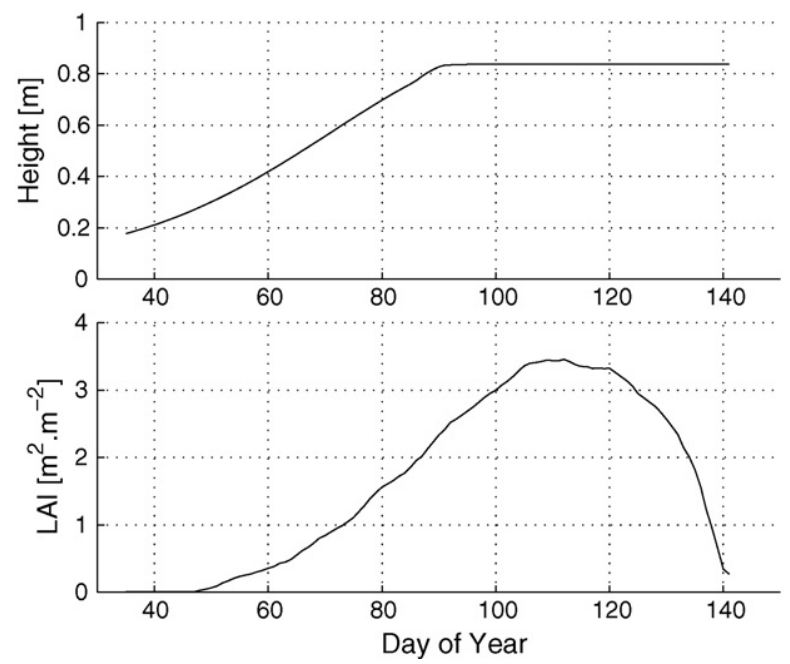

Fig. 3. Leaf area index and vegetation height measurements on R3B123 field in 2003.

38), with a growth peak on 20 April (DOY 110), followed by the senescence period until the end of May (see Fig. 3).

Near-continuous measurements have been recorded during the entire wheat season. Sensible heat flux was measured with a 3D sonic anemometer (CSAT3, Campbell Scientific, Logan, UT) at $3 \mathrm{~m}$ height. A $\mathrm{KH} 2 \mathrm{O}$ krypton hygrometer also measured the latent heat flux at this height. The soil heat flux is monitored by three heat flux plates at $1 \mathrm{~cm}$ below the surface, 2 plates at $10 \mathrm{~cm}$ and 1 plate located at $30 \mathrm{~cm}$. The net
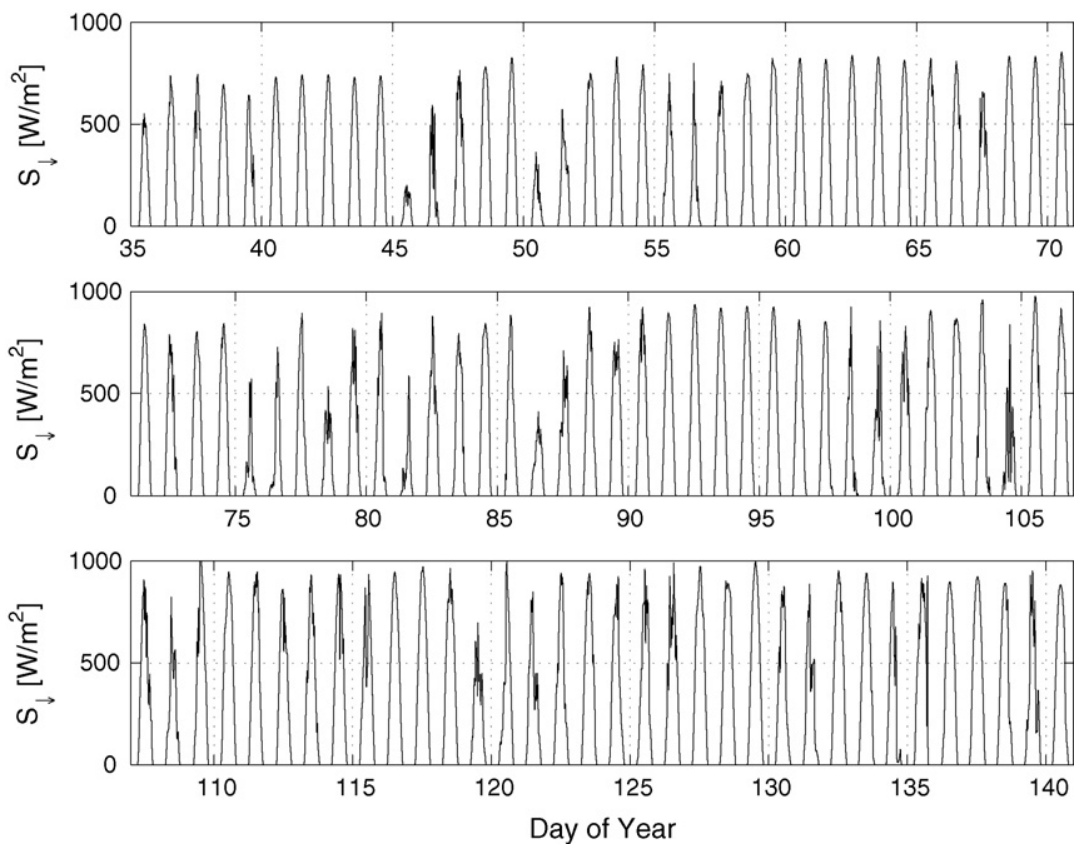

Fig. 4. Observed solar incoming shortwave radiation in $\mathrm{W} \mathrm{m}^{-2}$ over R3-B123 field in 2003. 
radiation is monitored by a CNR 1 located at $2 \mathrm{~m}$ above the ground. Moisture is monitored by several Time Domain Reflectometry (TDRs) located at 5, 10, 20, 30, $40,50 \mathrm{~cm}$ below the surface and soil temperatures are measured by some thermistances located at the same distance from the soil surface. Flux values derived from measurements that were obviously either too high or too low have been replaced by time-interpolated values, and when several errors occurred during one entire day, the flux data for that day was rejected.

The air temperature was monitored at $6 \mathrm{~m}$ height using Vaisala HMP45C probes, and the shortwave incoming radiation was recorded by a $3 \mathrm{~m}$ height with a CM5 pyranometer.

The meteorological conditions are highly variable. Solar incoming radiation varies between a diurnal maximum of $200 \mathrm{~W} \mathrm{~m}^{-2}$ for a February cloudy day to a diurnal maximum between 900 and $1000 \mathrm{~W} \mathrm{~m}^{-2}$ at the end of May (see Fig. 4). There is also a wide range of air temperatures with a minimum of $0{ }^{\circ} \mathrm{C}$ in February and a maximum of $38{ }^{\circ} \mathrm{C}$ by the end of May.

The average energy balance closure between the measured turbulent heat fluxes $H+\lambda E$ and the measured available energy $R_{\mathrm{n}}-G$ is $79 \%$ and they have $89 \%$ explained variance correspondence.

Past experimental EF studies were only able to study the EF behaviour during a few days because continuous experimental flux data are both complicated and costly to maintain. The R3-B123 meteorological and flux dataset offer measurements for more than 100 days. Fig. 5 shows the mean diurnal cycle of EF (named $\mathrm{EF}_{\text {cycle }}$ here after) using the measured latent and sensible heat fluxes averaged over the days 35-141.

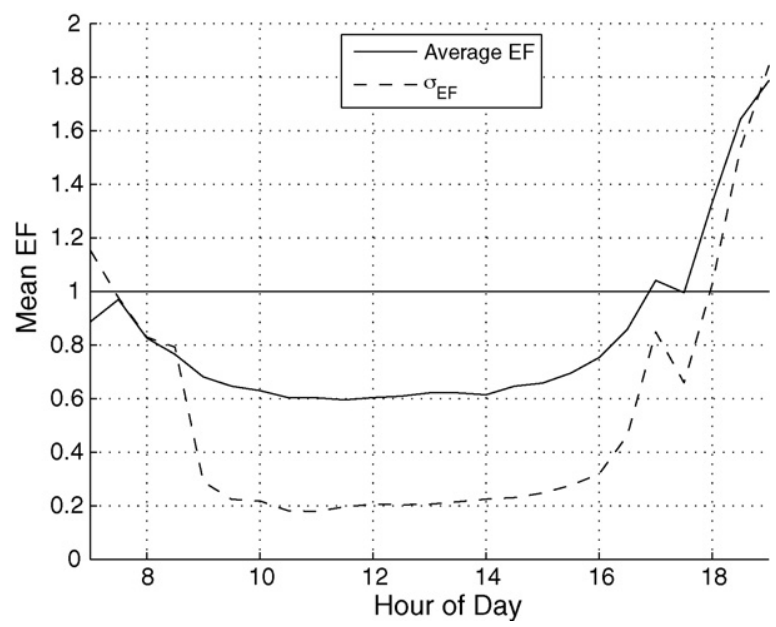

Fig. 5. Mean EF shape (solid line) and surrounding standard deviation (dashed line) using measured flux data on R3-B123 wheat parcel.
$\mathrm{EF}_{\text {cycle }}$ exhibits a typical concave-up shape with a minimum around 12PM (all times are referenced to local solar conditions so 12PM is local solar noon). The

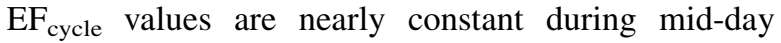
period. Near sunrise and sunset $\mathrm{EF}_{\text {cycle }}$ and its standard deviation increase sharply. Available energy that appears in the denominator of EF is small near these times. Therefore, the inclusion of early morning and late afternoon EF values in the estimation of daily EF can lead to non-negligible evapotranspiration estimation errors. The EF behaviour in those periods will clearly depend on environmental factors, soil water content, and phenological stage as well. Some of these influences were investigated in Lhomme and Elguero (1999) through SVAT modeling. This study builds on the same approach but extends it in important ways. Specifically the separate and distinct contributions of soil and vegetation and the phase shifts between the energy balance components are the subject of analyses. Application with the extended-duration field observation data allows for realistic experimental conditions.

\section{Lhomme and Elguero (1999) study}

Lhomme and Elguero (1999) analyzed the daytime pattern of EF using the Penman-Monteith single-source model coupled to a convective boundary layer model. The influence of both the micrometeorological factors and soil water availability on the EF daily course was investigated in this article. Lhomme and Elguero (1999) found that EF exhibits a typical concave-up shape, with a minimum around noon. EF also appeared to be relatively constant around mid-day yet always lower than the mean daily value. When available energy is not limiting, EF increases as soil water availability rises. Lhomme and Elguero (1999) also found that the air vapor saturation deficit only had a slight impact on EF amplitude and that wind velocity had almost no effect on EF.

However, in his approach Lhomme and Elguero (1999) assumed that the soil heat flux was a given fraction of the net radiation energy. Hence the soil heat flux $(G)$ and net radiation $\left(R_{\mathrm{n}}\right)$ were forced to be in phase. This can lead to large biases in the available energy $\left(R_{\mathrm{n}}-G\right)$ diurnal behaviour. Moreover $G$ is generally negative in the mid-afternoon, leading to a much smaller EF.

\section{Phase difference between $G$ and $R_{\mathrm{n}}$}

Many previous studies have shown that the phase difference between soil heat flux and net radiation is an 
important characteristic of surface energy balance (Fuchs and Hadas, 1972; Idso et al., 1975; Santanello and Friedl, 2003). The difference between these two fluxes appears in the denominator of EF. In fact it is the normalization of latent heat flux diurnal cycle by the diurnal cycle of this difference that explains the EF daily shape.

Usually EF exhibits a typical concave-up shape with a minimum in the early afternoon (see Fig. 5). Few studies have tried to theoretically explain the EF shape. Among those studies Crago (1996) and Lhomme and Elguero (1999) explained the diurnal shape using a single-source Penman-Monteith formulation for ET since they focused on closed-canopy vegetation. In those studies, the soil heat flux was considered either negligible or a constant small fraction of the net radiation. However, some studies (Clothier et al. (1986) and Kustas and Daughtry (1990)) have shown that the soil heat flux can be an important part of the energy budget and expressing it as a fraction of the incoming radiation does not represent the physics of conduction. Indeed, soil heat flux depends on many factors such as vegetation cover, soil type and moisture or time of day. In particular, Fuchs and Hadas (1972), Idso et al. (1975) and Santanello and Friedl (2003) found important phase difference between $G$ and $R_{\mathrm{n}}$ around solar noon.

In order to examine the nature of the phase differences between $G$ and $R_{\mathrm{n}}$, the SVAT model was integrated with the field experiment air micrometeorological forcing. The soil moisture and LAI were set at different sets of values in order to examine the fluxes under different surface conditions.

The LAI was kept constant during the period of simulation; three LAI values $(0.5,2.5$ and 4.5$)$ were used to find the average value of $f$ over the entire period with varying soil moisture conditions. Soil moisture is specified for the top $5 \mathrm{~cm}$ and the profile is allowed to reach hydrostatic equilibrium. An fraction $\mathrm{f}$ relating accumulated $G$ and $R_{\mathrm{n}}$ was then calculated for each integration as:

$f=\frac{\int_{\text {sunrise }}^{\text {sunset }} G(t) \mathrm{d} t}{\int_{\text {sunsise }}^{\text {sunset }} R_{\mathrm{n}}(t) \mathrm{d} t}$

Fig. 6 shows the difference between the SVAT modelled soil heat flux and the soil heat flux calculated as a fraction of the net radiation. The results represent the average diurnal cycle over the days of available field experiment air micrometeorology forcing data. The fraction $\mathrm{f}$ is taken from (1) in order to be consistent with the general climatology. The difference is negative during most of the day except in the morning, usually
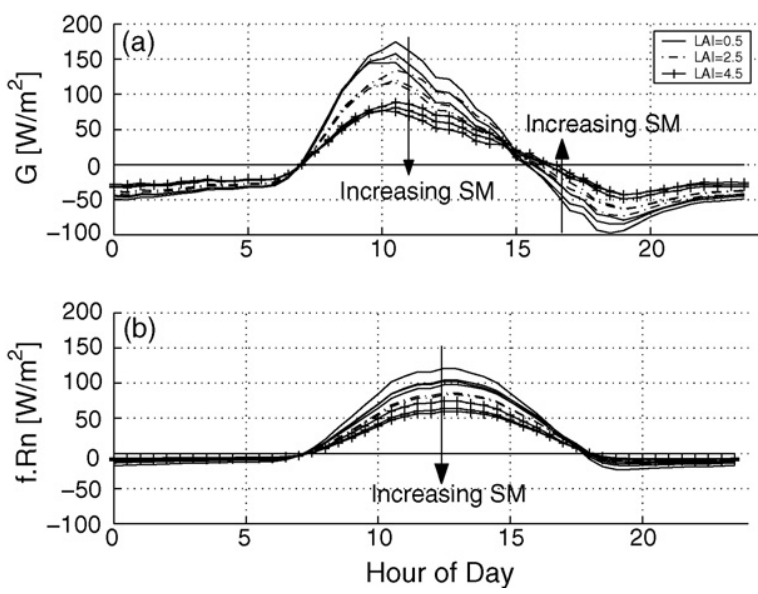

Fig. 6. Mean daily cycle of the SVAT modeled soil heat flux (a) and soil heat flux taken as fraction of the net radiation (b); for soil surface moisture values of $0.1,0.2,0.3 \mathrm{~m}^{3} \mathrm{~m}^{-3}$.

from 8 a.m. to 12.30 p.m. When $G$ is expressed as a fixed fraction of the incoming radiation, it is underestimating the soil heat flux in the morning and overestimating it during the rest of the day. Moreover, the difference is strongly dependent on LAI: it is increasing in sparse canopy cases because of the increasing fraction of radiation reaching the ground. The difference is lightly dependent on soil moisture. For high soil moisture contents, the large thermal inertia due to the water in the porous medium is compensated by a very small surface thermal gradient. Therefore, in the morning the surface soil heat flux is smaller in a wet case than in a dry case, it is the opposite in the late afternoon.

In Fig. 7 the soil heat flux difference (difference between the hourly flux from the simulation and that

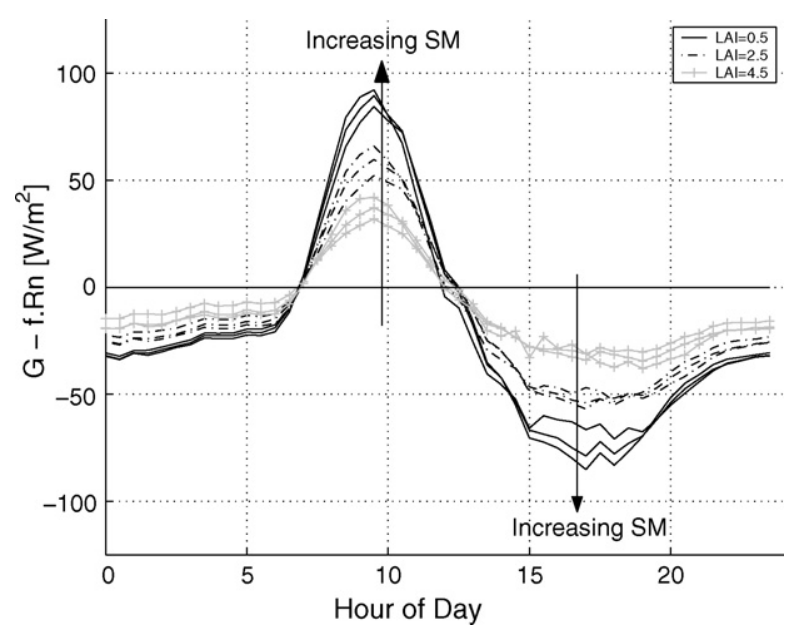

Fig. 7. Mean daily cycle of the difference between the SVAT modeled soil heat flux and the net radiation proportional heat flux; for soil surface moisture values of $0.1,0.2,0.3 \mathrm{~m}^{3} \mathrm{~m}^{-3}$. 
estimated using the constant $f$ ) is generally maximum in the mid morning, for all LAI and soil moisture conditions. It becomes negative in the mid afternoon essentially cancelling the net radiation at that time. This strong asymmetry in the errors of the in-phase assumption will have an effect on the diurnal shape of EF. In particular, the EF shape is less parabolic than the one found by Lhomme and Elguero (1999). Indeed the larger soil heat flux at the early daytime hours will sharpen the EF decrease at the beginning of the day. Then as $G$ becomes smaller and even negative in the afternoon, EF does not increase as rapidly as in the inphase case. The increase will be present as long as the soil water content is not high because the presence of liquid water decreases the amplitude of the soil heat flux.

\section{EF diurnal pattern dependencies}

The SVAT model is again used to analyze the surface factors (soil moisture and vegetation LAI) influence on the daytime self-preservation of EF. The SVAT is integrated with the days 35 to 141 hourly micrometeorology. The SVAT solves the ground heat flux explicitly and the flux is free to have phase difference with other surface energy balance components. In this way the contributions of the phase difference between the two constituitive components of available energy at the surface (denominator of EF) are accounted for in the analysis. The soil moisture and vegetation LAI are fixed for each simulation experiment in order to analyze the result for different surface moisture limitation and canopy cover regimes.

The instantaneous evaporative fraction is defined for total, soil, and canopy as (respectively):

$$
\begin{aligned}
\mathrm{EF}(t) & =\frac{\lambda E(t)}{R n(t)-G(t)} \\
\mathrm{EF}_{\mathrm{s}}(t) & =\frac{\lambda E_{\mathrm{s}}(t)}{R n_{\mathrm{s}}(t)-G(t)} \\
\mathrm{EF}_{\mathrm{c}}(t) & =\frac{\lambda E_{\mathrm{c}}(t)}{R n_{\mathrm{c}}(t)}
\end{aligned}
$$

Fig. 8 shows the diurnal behaviour of the total EF using (2) under different soil moisture and canopy cover conditions. The instantaneous EF values are averaged over the whole measurement period, i.e. days 35-141. In every case EF exhibits a convex diurnal shape as found using the in situ measured EF (Fig. 5). Soil moisture availability has a strong influence on EF because soil moisture is the main limiting factor for

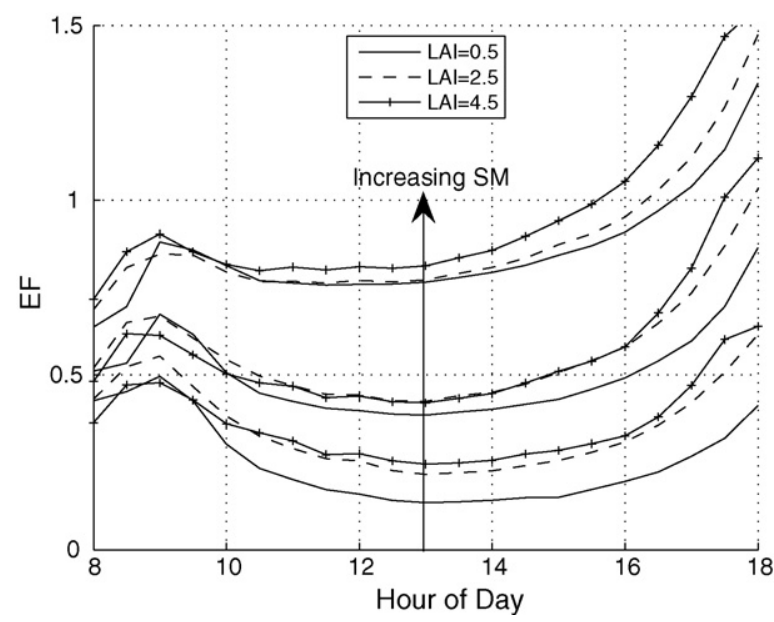

Fig. 8. Mean diurnal cycle of modeled evaporative fraction, from 4 January 2003 to 21 May 2003, for constant surface soil moisture values of $0.1,0.2$ and $0.3 \mathrm{~m}^{3} \mathrm{~m}^{-3}$, and constant LAI values of $0.5,2.5$ and 4.5.

latent heat flux. This is evident in the rise in EF, especially at mid-day, with increasing soil moisture. This is a reminder of the value of the EF diagnostic as a measure of surface control (soil moisture availability) on turbulent flux partitioning.

There are two main features in Fig. 8 that are noteworthy. First the sharp rise in EF during late afternoon is sensitive to LAI and vegetation cover. When vegetation cover is full the rise is more pronounced and the daytime self-preservation is less evident. Second the instantaneous value of EF exceeds unity during late afternoon especially for well-watered

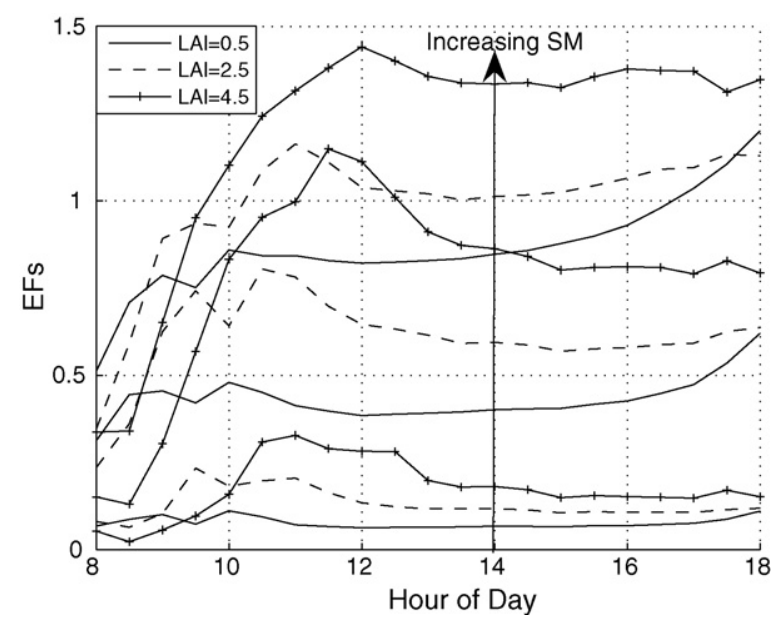

Fig. 9. Mean diurnal cycle of modeled soil evaporative fraction, from 4 January 2003 to 21 May 2003, for constant surface soil moisture values of $0.1,0.2$ and $0.3 \mathrm{~m}^{3} \mathrm{~m}^{-3}$, and constant LAI values of $0.5,2.5$ and 4.5. 

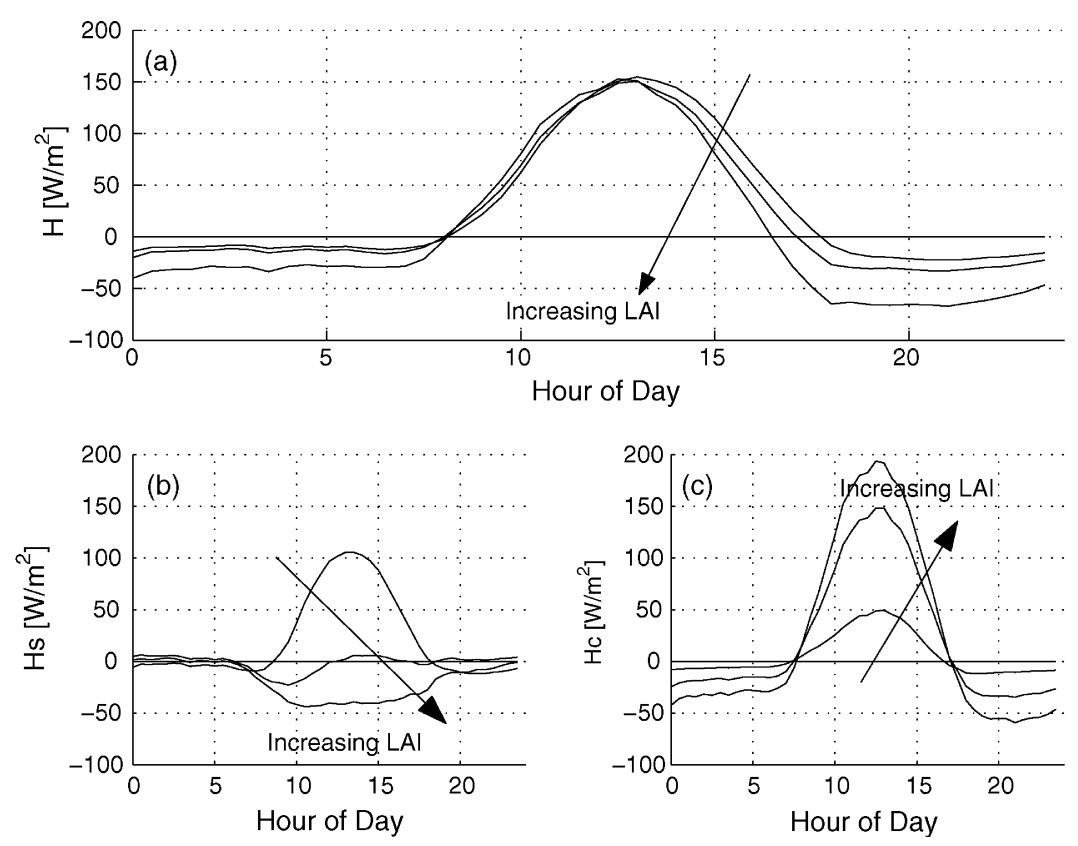

Fig. 10. Diurnal course of the total sensible heat flux (a), soil sensible heat flux (b), and canopy sensible heat flux (c) for a medium LAI value of 2.5 , and constant surface soil moisture values of $0.1,0.25$ and $0.4 \mathrm{~m}^{3} \mathrm{~m}^{-3}$.

and fuller canopies. These two features can be further broken down and analyzed using the SVAT model data.

Fig. 9 shows the bare soil component $\mathrm{EF}_{\mathrm{s}}$ based on application of (3) and averaging over the entire experiment period. $\mathrm{EF}_{\mathrm{s}}$ is generally increasing (rapidly rising to its mid-day value) until noon and then slowly decreasing in the afternoon until sunset. Contrary to the total $\mathrm{EF}$, the soil evaporative fraction $\mathrm{EF}_{\mathrm{s}}$ is a strongly increasing function of LAI. The late afternoon rapid rise observed for EF in Fig. 8 is not apparent for the bare soil fraction. In this respect the bare soil fraction daytime self-preservation of EF may be a better assumption. One noticeable feature is that, when LAI increases, the soil evaporative fraction $\mathrm{EF}_{\mathrm{s}}$ exceeds unity when soil moisture is not limiting. Under full vegetation cover conditions the canopy temperature increases as it receives more energy, and the soil temperature is reduced due to the increasing shadow. For high LAI cases, a temperature inversion can occur leading to a negative soil sensible heat flux $H_{\mathrm{s}}$ and therefore a soil evaporative fraction $\mathrm{EF}_{\mathrm{s}}$ greater than unity. This effect is particularly strong for high LAIs and high soil moisture conditions that clearly increase the possibility of soil-canopy temperatures inversion. This effect is confirmed when the average diurnal course of the sensible heat fluxes (total $H$, soil $H_{\mathrm{s}}$, and canopy $H_{\mathrm{c}}$ ) are plotted as a function of daytime hour for $\mathrm{LAI}=2.5$, the mid-range value (Fig. 10). Whereas the total sensible heat flux to the atmosphere is generally positive (Fig. 10a), the soil and canopy components (Fig. 10b and c) show that thermal inversions are prevalent especially in the late afternoon and for bare soils. The result is a general downward sensible heat flux $H$ during late afternoon and decrease in the denominator of instantaneous EF. The impact is a sharp rise in EF during the late afternoon (Figs. 5 and 8). The value of daytime EF diagnostic is lost if averaging includes these hours of the day.

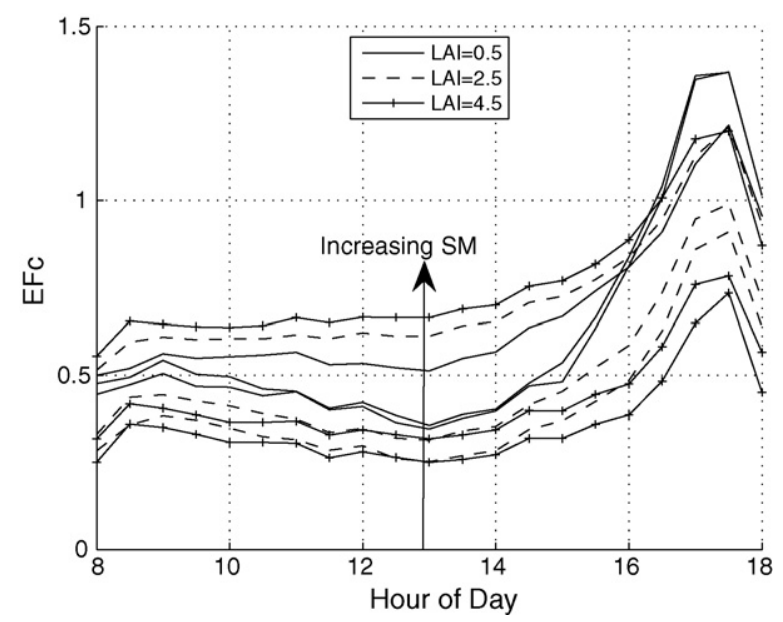

Fig. 11. Mean diurnal cycle of modeled canopy evaporative fraction, from 4 January 2003 to 21 May 2003, for constant surface soil moisture values of $0.1,0.2$ and $0.3 \mathrm{~m}^{3} \mathrm{~m}^{-3}$, and constant LAI values of $0.5,2.5$ and 4.5 . 
The results can be viewed from another angle with similar understanding. Fig. 11 shows the canopy $\mathrm{EF}_{\mathrm{c}}$ averaged over the experiment period. The canopy evaporative fraction diurnal course is generally constant in the morning and increases sharply in the afternoon. Thereby a constant canopy evaporative fraction assumption can lead to large errors in evapotranspiration estimate if this sharp deviation in the afternoon due to thermal inversion in canopy-covered landscapes is not included.

\section{EF covariation With micrometeorological factors}

More insight into the factors that affect the degree to which daytime EF self-preservation is possible is obtained through understanding the link between EF and micrometeorological parameters. Micrometeorological parameters include air temperature, solar incoming radiation, wind speed and temperature gradient near the surface $T_{\text {ro }}-T_{a}$, where $T_{\text {ro }}$ is the land surface temperature (LST). All these factors affect the surface turbulent fluxes. The temporal covariations can be estimated from the SVAT simulations. Again the SVAT is forced with the days 35-141 air micrometeorological time-series but the surface regimes (represented by soil moisture and vegetation LAI) are fixed at a series of values in order to analyze the regime-dependence of the covariances. The results are stratified for varying vegetation cover (LAI) and soil moisture conditions.

Here daytime EF is defined as

$$
\begin{aligned}
\langle\mathrm{EF}\rangle_{\text {daily }} & =\frac{\int_{\text {suniset }}^{\text {sunset }} \lambda E(t) \mathrm{d} t}{\int_{\text {sunrise }}^{\text {sunset }}[H(t)+\lambda E(t)] \mathrm{d} t} \\
& =\frac{\int_{\text {sunrise }}^{\text {sunset }} \lambda E(t) \mathrm{d} t}{\int_{\text {sunrise }}^{\text {sunset }}\left[R_{\mathrm{n}}(t)-G(t)\right] \mathrm{d} t}
\end{aligned}
$$

The principal source of available energy at the surface is solar radiation. Fig. 12a shows the temporal correlation between EF and incoming solar radiation on a daily timescale. The correlation is generally weak and exhibits two different regimes. For soil moisture values less than $0.2\left[\mathrm{~m}^{3} \mathrm{~m}^{-3}\right]$ (site specific), evapotranspiration is water limited leading to a decorrelation with solar incoming radiation (Fig. 12b). For high soil moisture contents, latent heat flux is very positively correlated to the solar incoming radiation, as this latter leads evapotranspiration in this case. Available energy, $A=R_{\mathrm{n}}-G=\lambda E+H$, which appears as the denominator of EF, is always positively correlated with solar incoming radiation as it the mains source of available energy. Those two behaviours explain the EF correlation with solar
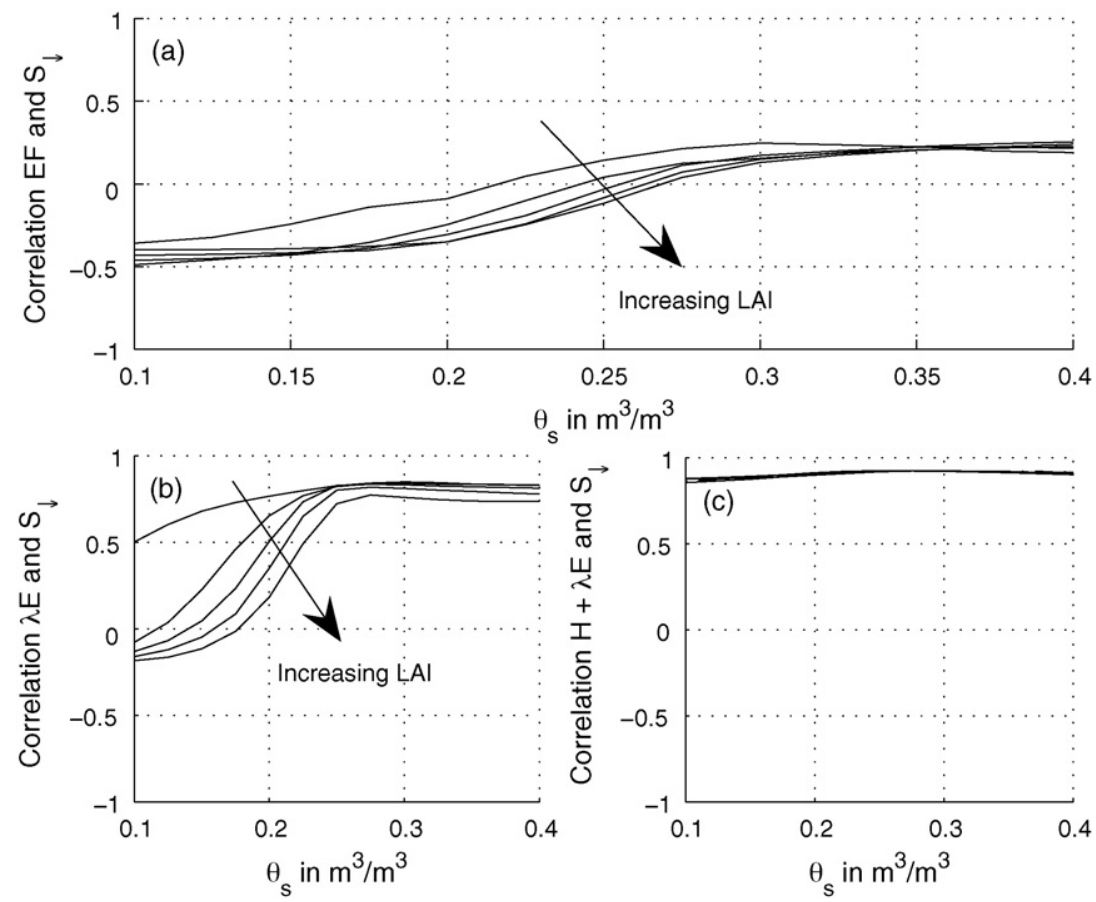

Fig. 12. Cross-correlation between (a) EF, (b) $\mathrm{IE}$, (c) $H+\lambda E$ and solar incoming radiation over the 4 January-21 May 2003 modeling period for constant LAI values of $0.5,1.5,2.5,3.5$ and 4.5. 


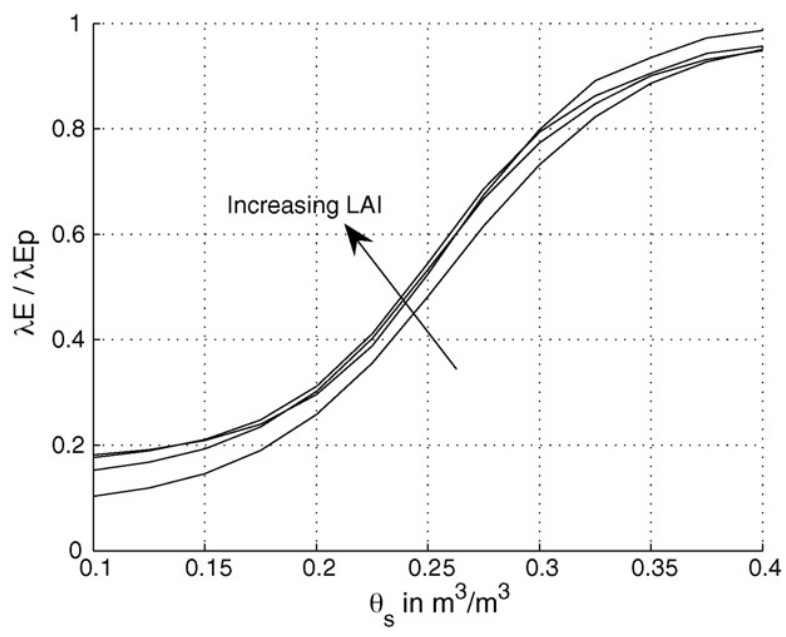

Fig. 13. Ratio of averaged daily latent heat flux over average daily potential latent heat flux for $\mathrm{LAI}=1,2,3$ and 4 .

incoming radiation. This soil moisture-dependent transition from water-limited evaporation regime to energylimited evaporation regime is highly model-dependent and, even in the field, dependent on factors such as rooting depth, plant species, and soil texture.

Fig. 13 shows the general shape of this function for the experiment here. The potential evapotranspiration is defined as the model evapotranspiration for vanishing surface resistance and minimum stomatal resistance. The average ratio of evapotranspiration to potential evapotranspiration shows a strong dependence on soil moisture and only a weak dependence on LAI.

Another important forcing factor driving turbulent exchange at the surface, beside the dominant role of incoming solar radiation in available energy, is windspeed. Ideally the EF diagnostic should be independent of this factor in its dynamics.

The correlation between EF and the wind speed is generally small as shown in Fig. 14. This result agrees with Lhomme and Elguero (1999) who also found that there was almost no influence of wind speed on EF. Again here the EF definition is broken down in order to understand the contributing reasons and their dependence on LAI and soil moisture. The overall decorrelated effect is due to compensation between the latent heat flux and available energy correlations. When the soil water content is limiting the latent heat flux remains small and the wind speed has almost no influence on its fluctuations (Fig. 14b). Available energy is only slightly correlated with wind speed through the decrease in surface temperature when wind speed increases, and consequently, the increase in net radiation. Therefore, the EF correlation with the wind speed remains small for low soil water contents. While soil water becomes more available wind speed becomes one of the main limiting factors of latent heat flux amplitude. Under these conditions latent heat flux is strongly correlated with the wind speed value (Fig. 14b) leading to a
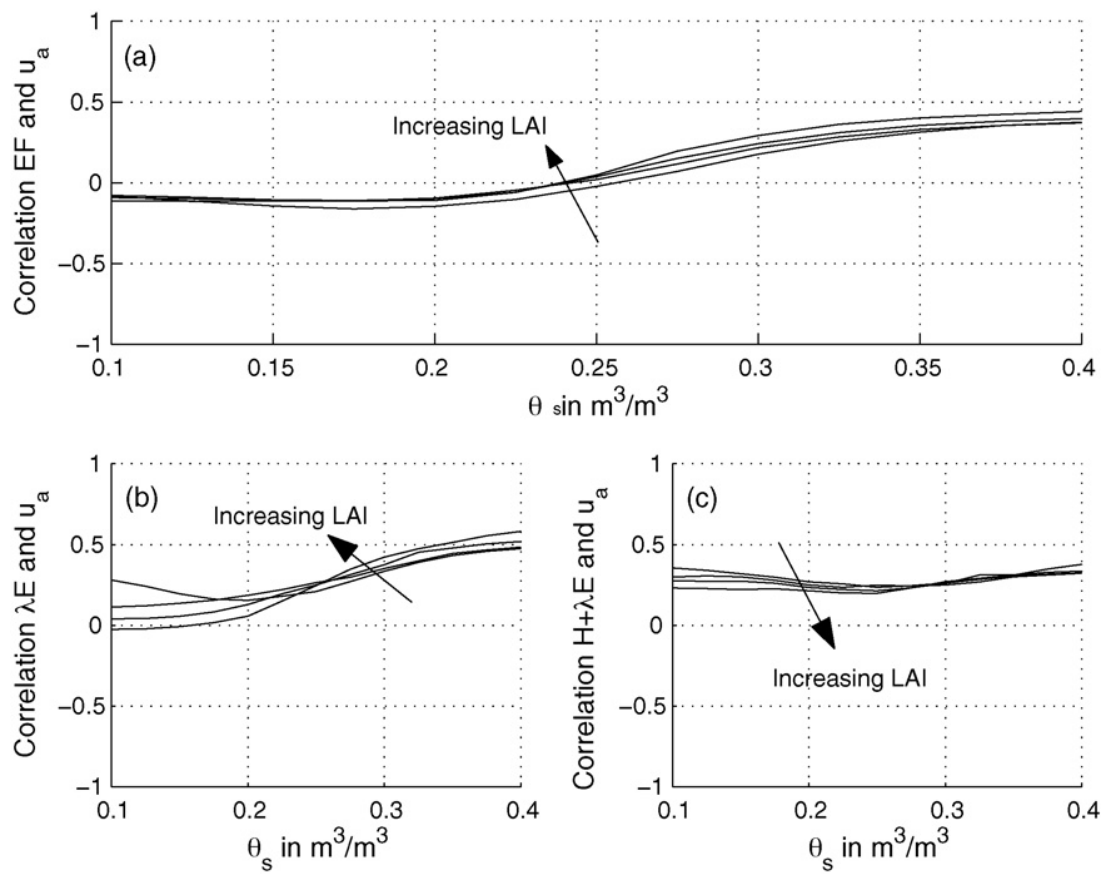

Fig. 14. Cross-correlation between (a) EF, (b) $\lambda E$, (c) $H+\lambda E$ and wind speed over the 4 January-21 May 2003 modeling period for constant LAI values of $0.5,1.5,2.5,3.5$ and 4.5 . 

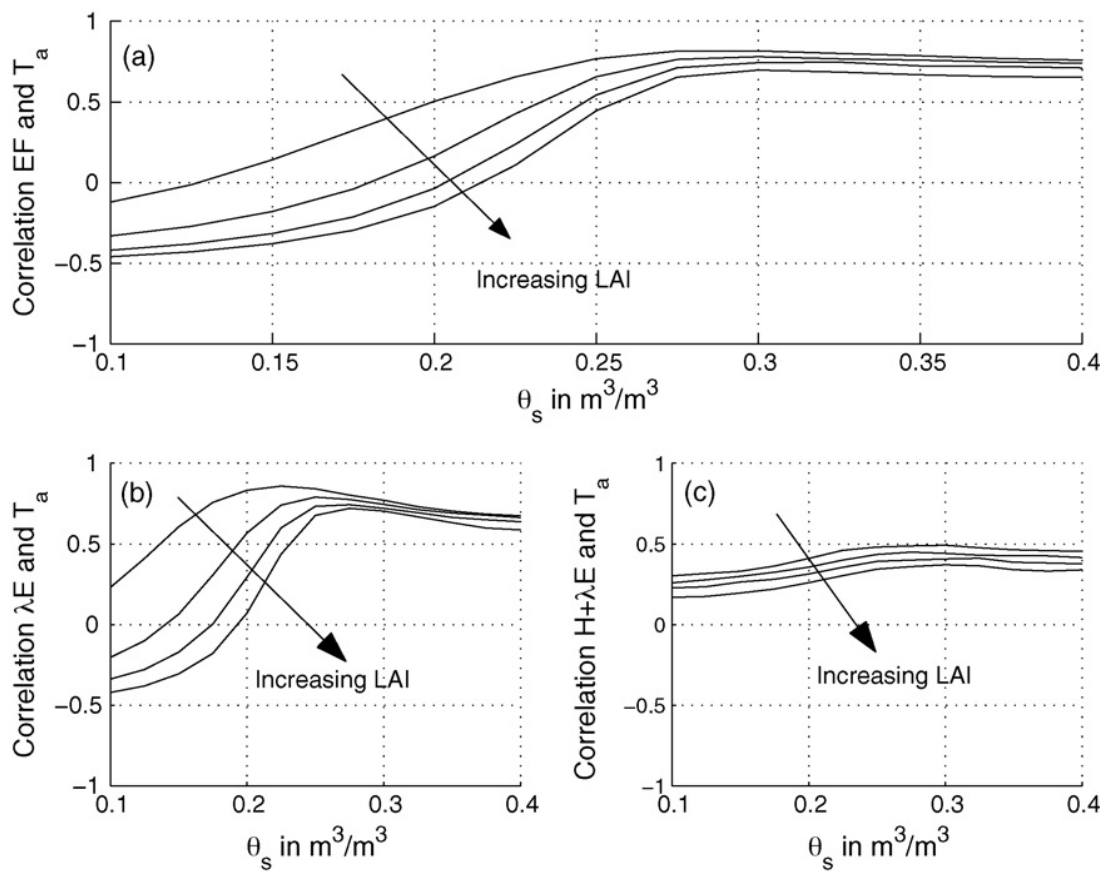

Fig. 15. Cross-correlation between (a) EF, (b) $\lambda E$, (c) $H+\lambda \mathrm{E}$ and air temperature over the 4 January-21 May 2003 modeling period for constant LAI values of $0.5,1.5,2.5,3.5$ and 4.5 .

stronger correlation between EF and wind speed. Yet the stronger correlation of the latent heat flux is compensated by the non-negligible correlation between available energy and wind speed (Fig. 14c).

Of practical consequence in remote sensing approaches to EF determination is the dependence of EF on observable states of the system such as physical temperatures. The correlation between $\mathrm{EF}$ and air temperature is strong and positive for high soil water content and low LAI (Fig. 15). Under water-limited evaporation regime conditions evapotranspiration is forcibly reduced and generally decoupled from micrometeorological conditions. This is evident in both Fig. 15a and $\mathrm{b}$ for correlations when the soil moisture is low. The degree of decorrelation is strongly dependent on LAI as well. The bare soil surface can still evaporate even at very low soil moisture content, leading to a stronger correlation between evaporation and air temperature for low soil moisture. The plant though experiences stress and shuts down transpiration leading to the decoupling. Available energy is positively but weakly correlated to the air temperature regardless of the dominant soil moisture or vegetation canopy conditions (Fig. 15c). Unlike incoming solar radiation and wind speed, the compensating effect of the EF numerator and $\mathrm{EF}$ denominator are absent in the case of air temperature. However, the sign and magnitude of the EF-air temperature correlation are highly dependent on the soil moisture and vegetation canopy conditions. In this respect when soil moisture is limiting it is advantageous for the definition of EF that it does not depend on air temperature. When the surface evaporation regime is energy-limited, then air temperature is a good indicator of EF. Yet the results are not totally reliable since the transition is not well-defined (in both models and field).

A more physically derived temperature diagnostic for turbulent flux estimation and for the determination of partitioning among sensible and latent heat fluxes needs to be used. This temperature measure is based on the difference between surface radiative and air temperature prognostics, namely $T_{\mathrm{r} 0}-T_{\mathrm{a}}$. Sensible heat flux is clearly strongly correlated with $T_{\mathrm{r} 0}-T_{\mathrm{a}}$ (of the order of 0.95) as shown in Fig. 16a because $T_{\mathrm{r} 0}-T_{\mathrm{a}}$ is a direct driver of sensible heat flux. As shown in Fig. $6 \mathrm{~b}$, the latent heat flux exhibits two distinct regimes. For the water limited regime, $T_{\mathrm{r} 0}-T_{\mathrm{a}}$ plays the role of an indicator of the plant stress. Hence a strong negative correlation occurs for high LAI and low soil moisture content. Far enough above wilting point ( $w_{\text {wilt }}=0.14\left[\mathrm{~m}^{3} \mathrm{~m}^{-3}\right]$ in our case), then root zone soil moisture is no longer a limiting factor for transpiration and this latter plays the role of a regulator on the surface temperature by preventing the canopy temperature to deviate far from air temperature. Hence a negative correlation between ET and $T_{\mathrm{r} 0}-T_{\mathrm{a}}$ emerges and the correlation will once again decrease (Fig. 16b). 

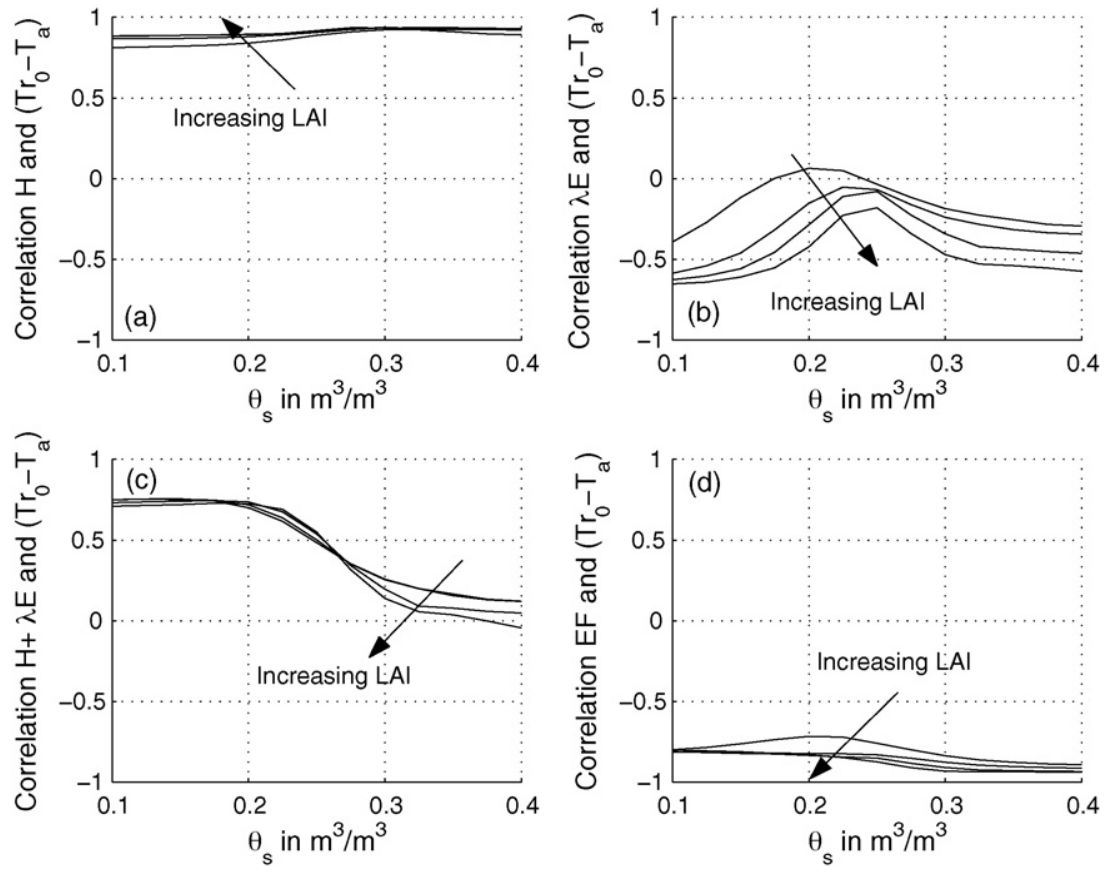

Fig. 16. Cross-correlation between (a) $\mathrm{H}$, (b) $\lambda E$, (c) $H+\lambda E$, and (d) $\mathrm{EF}$ and the difference between the radiative and air temperatures over the 4 January-21 May 2003 modeling period for constant LAI values of 0.5, 1.5, 2.5, 3.5 and 4.5.

For low soil moisture values, $H$ is dominant over $\lambda E$ and hence the sum is highly and positively correlated with $T_{\mathrm{r} 0}-T_{\mathrm{a}}$. Therefore, the available energy is also highly and positively correlated with $T_{\mathrm{r} 0}-T_{\mathrm{a}}$. As soil moisture increases, latent heat flux dominates sensible heat flux. This will lead to an almost decorrelation between available energy and $T_{\mathrm{r} 0}-T_{\mathrm{a}}$ under energylimited evaporation regimes, as seen on Fig. 16c

Because of these effects (most clearly evident in Figs. $16 \mathrm{~b}$ and $\mathrm{c}$ for $\lambda E$ and $\lambda E+H$ correlation with $T_{\mathrm{r} 0}-T_{\mathrm{a}}$ ), EF itself is very strongly and negatively correlated with $T_{\mathrm{r} 0}-T_{\mathrm{a}}$ as shown in Fig. 16d. This constitutes a promising result as this temperature measure could become the building block for estimating EF based on observations and for model design. Radiative temperature can be obtained through remote sensing imagery and air temperature can be estimated based on micrometeorological station data or atmosphere analyses. Air temperature is generally more spatially correlated due to atmospheric advection and mixing. This may be a fruitful path ahead for remote sensing estimation of EF and eventually evapotranspiration.

\section{Time-of-day representativeness of EF}

A relevant question is if there is a time of day when $\mathrm{EF}$ is most representative of the effective daily value that is useful for evapotranspiration estimation. This has relevance for remote sensing-based estimation of EF based on sun-synchronous observations. Fig. 17 shows that the hour of EF estimation is important to evapotranspiration estimation. Due to the inherent convex shape of EF during daytime with a minimum around noon, there will always be an underestimation of the daily ET using mid-day EF. Moreover, when using a

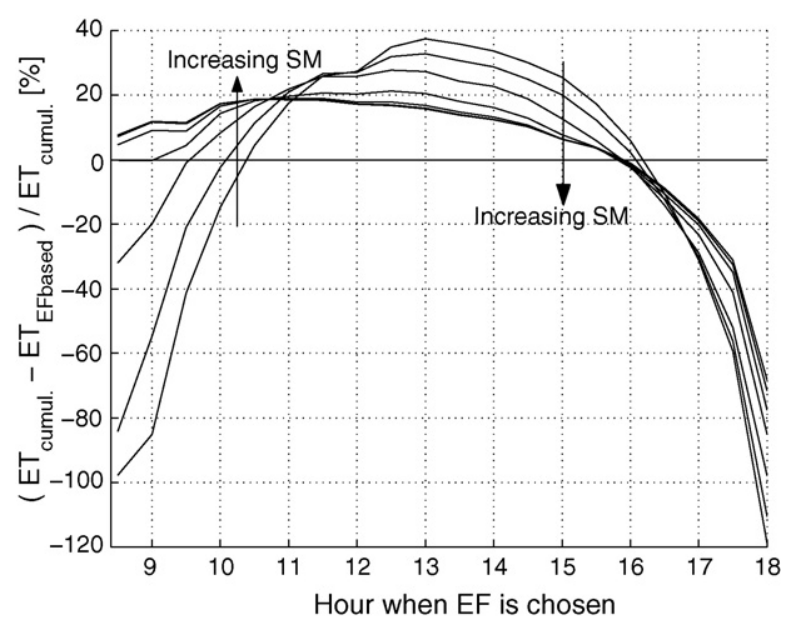

Fig. 17. Relative cumulative absolute evapotranspiration error [\% $\times 100]$ from days 35 to 141 using the EF value determined for different hours of the day, for constant surface soil moisture of 0.1 , $0.15,0.2,0.25,0.3,0.35$ and $0.4 \mathrm{~m}^{3} \mathrm{~m}^{-3}$. 
measure of EF between 11 a.m. and 3 p.m., the estimation error of the cumulative ET ranges between 20 and $40 \%$. Therefore, using a constant EF assumption and a LST image around noon can lead to large ET estimation errors. It seems difficult to give a global best hour of measurements valid for any site, because the choice of hour will depend on the surface and meteorological conditions of the study site. However, there does seem to be, for a given LAI condition, a local hour (here 4 p.m.) such that the soil moisture dependencies are minimum. This result has to be confirmed further with different models and field experiment locations.

\section{Conclusions}

This study is aimed at diagnosing and providing insights into the diurnal behaviour of $\mathrm{EF}$ and its link with the soil moisture, vegetation canopy and major atmospheric conditions. In particular EF is found to be almost independent of the major forcing factors, namely incoming solar radiation and wind speed, due to compensating effects that are traced to the elements of EF itself. However, these compensating effects can have strong dependence on soil moisture availability and canopy cover. Furthermore the temperature difference $T_{\mathrm{r} 0}-T_{\mathrm{a}}$ is demonstrated to be well-correlated with the values of EF. This constitutes a promising indicator and tool for remote sensing applications, as this strong correlation for any kind of conditions will permit to reach a better estimate of the instantaneous EF. The daytime self-preservation of EF is an assumption that can be revised in order to obtain a better estimate of evapotranspiration. The convex shape of EF is ubiquitous and largely due to thermal inversions under the vegetation canopy. Again the degree to which the EF daytime self-preservation is relevant or breaks down is dependent on the evaporation regime (water-limited versus energy-limited) and on the fraction vegetation cover. This study also showed that the soil component of EF, namely EFs, can safely be assumed as constant contrary to the canopy component EFc. This constitutes an important result for assimilation of LST for dual-source surface energy balance models, as selfpreserved daily parameters can be estimated more easily.

\section{Acknowledgments}

This work was carried out with support from the grant titled "Direct Assimilation of Remotely Sensed Land Surface Temperature for the Estimation of Surface
Fluxes" from the National Aeronautics and Space Administration to Massachusetts Institute of Technology. The authors thank the SUDMED project team that shared the field experiment data from the region of Marrakech, Morocco.

\section{Appendix A. Model description}

This study is based on the soil-vegetation-atmosphere-transfer (SVAT) model called ICARE-SVAT. This model is calibrated and tested on two wheat parcels and one olive tree orchard during the 2002 and 2003 SUDMED field experiments.

\section{A.1. Soil module}

The evolution of ground temperatures is characterized by a classical heat diffusion equation following the approach introduced by De Vries (1958). The soil horizon is divided into different layers with their own soil properties and soil water content and temperature states. The horizontal diffusion is neglected leading to a one-dimensional vertical diffusive equation

$$
\left\{\begin{array}{c}
c \frac{\partial T}{\partial t}=\frac{\partial G}{\partial z} \\
G=k_{\mathrm{T}} \frac{\partial T}{\partial z}
\end{array}\right.
$$

Appendix B presents lists of symbols and their units.

The evolution of the soil moisture content is based on Boone (2002) diffusive moisture scheme in a snow-free case

$\left\{\begin{array}{l}\frac{\partial w}{\partial t}=-\frac{\partial F}{\partial z} \quad \text { when } 0<w \leq w_{\text {sat }} \\ F=-k \frac{\partial}{\partial z}(\psi+z)-\frac{D}{\rho_{\mathrm{w}}} \frac{\partial \psi}{\partial z}-K_{\mathrm{d}}\end{array}\right.$

The soil water content is the water state variable of the SVAT model. To calculate the water matric potential $\psi$ the Brooks and Corey (1966) relationship between the soil water content and the soil matric potential is used

$\psi_{2}\left(w_{2}\right)=\psi_{\text {sat }}\left(\frac{w_{2}}{w_{\text {sat }}}\right)^{-B}$

where $B$ is the shape parameter of the retention curve. The parameters of the curves were calibrated based on soil samples from SUDMED.

The discretized equations are solved using a CrankNicholson algorithm, with a Crank-Nicholson parameter $\mathrm{CN}=1 / 2$ with 16 nodes. 


\section{A.2. Dual-source energy fluxes}

The approach used for the soil and vegetation exchange of heat and water with the atmosphere is the one-dimensional, two-layer resistance network introduced by Shuttleworth and Wallace (1985) (see Fig. 1), in which soil and vegetation are independent sinks/ sources of heat fluxes. In this field experiment case (sparse vegetation) the series resistance approach performed better than the parallel formulation of Boulet et al. (1999). The net radiation available above the canopy is divided into a soil and canopy radiation

$R_{\mathrm{n}}=R_{\mathrm{n}}^{\mathrm{s}}+R_{\mathrm{n}}^{\mathrm{c}}$

$$
\begin{aligned}
R_{\mathrm{n}}^{\mathrm{c}} & =\left(1-b_{0}\right)\left(1-\alpha_{\mathrm{c}}\right)\left[\frac{1+\alpha_{\mathrm{s}} b_{0}}{1-\left(1-b_{0}\right) \alpha_{\mathrm{s}} \alpha_{\mathrm{c}}}\right] S_{\downarrow} \\
& +\left[\left(1-b_{0}\right) \varepsilon_{\mathrm{c}}+\frac{\left(1-b_{0}\right) b_{0}\left(1-\varepsilon_{\mathrm{s}}\right) \varepsilon_{\mathrm{c}}}{1-\left(1-b_{0}\right)\left(1-\varepsilon_{\mathrm{s}}\right)\left(1-\varepsilon_{\mathrm{c}}\right)}\right] L_{\downarrow} \\
& -\left(1-b_{0}\right) \varepsilon_{\mathrm{c}}\left[1+\frac{b_{0}\left(1-\varepsilon_{\mathrm{s}}\right)+\varepsilon_{\mathrm{s}}}{1-\left(1-b_{0}\right)\left(1-\varepsilon_{\mathrm{s}}\right)\left(1-\varepsilon_{\mathrm{c}}\right)}\right] \sigma T_{\mathrm{c}}^{4} \\
& +\left[\frac{\left(1-b_{0}\right) \varepsilon_{\mathrm{s}} \varepsilon_{\mathrm{c}}}{1-\left(1-b_{0}\right)\left(1-\varepsilon_{\mathrm{s}}\right)\left(1-\varepsilon_{\mathrm{c}}\right)}\right] \sigma T_{\mathrm{s}}^{4}
\end{aligned}
$$

$$
\begin{aligned}
R_{\mathrm{n}}^{\mathrm{s}}= & \frac{b_{0}\left(1-\alpha_{\mathrm{s}}\right)}{1-\left(1-b_{0}\right) \alpha_{\mathrm{s}} \alpha_{\mathrm{c}}} S_{\downarrow} \\
& +\left[\frac{\left(1-b_{0}\right) \varepsilon_{\mathrm{s}} \varepsilon_{\mathrm{c}}+b_{0} \varepsilon_{\mathrm{s}}}{1-\left(1-b_{0}\right)\left(1-\varepsilon_{\mathrm{s}}\right)\left(1-\varepsilon_{\mathrm{c}}\right)}\right] L_{\downarrow} \\
& -\left[\frac{\left(1-b_{0}\right) \varepsilon_{\mathrm{s}} \varepsilon_{\mathrm{c}}+\varepsilon_{\mathrm{s}} b_{0}}{1-\left(1-b_{0}\right)\left(1-\varepsilon_{\mathrm{s}}\right)\left(1-\varepsilon_{\mathrm{c}}\right)}\right] \sigma T_{\mathrm{s}}^{4} \\
& +\left[\frac{\left(1-b_{0}\right) \varepsilon_{\mathrm{s}} \varepsilon_{\mathrm{c}}}{1-\left(1-b_{0}\right)\left(1-\varepsilon_{\mathrm{s}}\right)\left(1-\varepsilon_{\mathrm{c}}\right)}\right] \sigma T_{\mathrm{c}}^{4}
\end{aligned}
$$

which follows Taconet et al. (1986a,b). The energy budget is closed for both the canopy and the soil compartments

$R_{\mathrm{n}}^{\mathrm{s}}-H_{\mathrm{s}}-\lambda E_{\mathrm{s}}-G=0$

$R_{\mathrm{n}}^{\mathrm{c}}-H_{\mathrm{c}}-\lambda E_{\mathrm{c}}=0$

As proposed by Shuttleworth and Wallace (1985), a mean air flow at the source level is used. Energy exchange is located between this source and the soil, the canopy, or the above canopy reference height. The heat fluxes are expressed as a function of the resistances, temperatures and vapor pressures at the different nodes of interest.
The latent heat fluxes can be expressed with those resistances as

$$
\begin{aligned}
& \lambda E_{\mathrm{s}}=\frac{\rho c_{\mathrm{p}}}{\gamma} \frac{e^{*}\left(T_{\mathrm{s}}\right)-e_{0}}{r_{\mathrm{as}}+r_{\mathrm{ss}}} \\
& \lambda E_{\mathrm{c}}=\frac{\rho c_{\mathrm{p}}}{\gamma} \frac{e^{*}\left(T_{\mathrm{c}}\right)-e_{0}}{r_{\mathrm{ac}}+r_{\mathrm{sc}}} \\
& \lambda E=\frac{\rho c_{\mathrm{p}}}{\gamma} \frac{e_{0}-e_{\mathrm{a}}}{r_{\mathrm{a}}}
\end{aligned}
$$

Similarly the sensible heat fluxes are expressed as

$$
\begin{aligned}
& H_{\mathrm{s}}=\rho c_{\mathrm{p}} \frac{T_{\mathrm{s}}-T_{0}}{r_{\mathrm{as}}} \\
& H_{\mathrm{c}}=\rho c_{\mathrm{p}} \frac{T_{\mathrm{c}}-T_{0}}{r_{\mathrm{ac}}} \\
& H=\rho c_{\mathrm{p}} \frac{T_{0}-T_{\mathrm{a}}}{r_{\mathrm{a}}}
\end{aligned}
$$

Where $T_{0}$ is the mean temperature value at the source level within the canopy. Based on (A12)-(A14) $T_{0}$ can be explicitly written as

$$
T_{0}=\frac{\left(T_{\mathrm{a}} / r_{\mathrm{a}}\right)+\left(T_{\mathrm{s}} / r_{\mathrm{as}}\right)+\left(T_{\mathrm{c}} / r_{\mathrm{ac}}\right)}{\left(1 / r_{\mathrm{a}}\right)+\left(1 / r_{\mathrm{as}}\right)+\left(1 / r_{\mathrm{ac}}\right)}
$$

Similarly based on (A9)-(A11), $e_{0}$ can be explicitly written as

$e_{0}=\frac{e_{\mathrm{a}} / r_{\mathrm{a}}+e^{*}\left(T_{\mathrm{s}}\right) /\left(r_{\mathrm{as}}+r_{\mathrm{ss}}\right)+e^{*}\left(T_{\mathrm{c}}\right) /\left(r_{\mathrm{ac}}+r_{\mathrm{sc}}\right)}{\left(1 / r_{\mathrm{a}}\right)+1 /\left(r_{\mathrm{as}}+r_{\mathrm{ss}}\right)+1 /\left(r_{\mathrm{ac}}+r_{\mathrm{sc}}\right)}$

All aerodynamic resistances are based on Choudhury and Monteith (1988) with inclusion of atmospheric static-stability correction. The aerodynamic resistance $r_{\mathrm{a}}$ (for heat and water vapor) is calculated as in Brutsaert (1982)

$r_{\mathrm{a}}=\frac{\ln \left(\left(z_{\mathrm{r}}-d\right) / z_{0_{\mathrm{h}}}\right)-\psi_{\mathrm{h}}\left(\left(z_{\mathrm{r}}-d\right) / L_{\mathrm{mo}}\right)}{K u^{*}}$

where

$u^{*}=\frac{K u_{\mathrm{a}}}{\ln \left(\left(z_{\mathrm{r}}-d\right) / z_{0}\right)-\psi_{\mathrm{m}}\left(\left(z_{\mathrm{r}}-d\right) / L_{\mathrm{mo}}\right)}$

$\psi_{\mathrm{h}}$ and $\psi_{\mathrm{m}}$ represent the integral adiabatic correction functions, respectively, for heat and momentum given by Paulson (1970). The stability correction is computed using the Monin-Obukhov length scale

$L_{\mathrm{mo}}=\frac{-\rho c_{\mathrm{p}} T_{\mathrm{a}} u^{*^{3}}}{K g_{0} H}$ 
The zero displacement height and the roughness length for momentum $z_{0}$ are determined following Choudhury and Monteith (1988) for wheat

$d=1.1 h \ln \left(1+X^{1 / 4}\right)$

$X=C_{\mathrm{d}}\left(\mathrm{LAI}_{\text {green }}+\mathrm{LAI}_{\mathrm{dry}}\right)$

$z_{0}= \begin{cases}z_{0_{\mathrm{s}}}+0.3 h X^{1 / 2}, & 0<X \leq 0.2 \\ 0.3 h(1-d / h), & 0.2<X \leq 1.5\end{cases}$

where $C_{\mathrm{d}}$ is the main drag coefficient assumed to be uniform within the canopy.

The aerodynamic resistance between ground surface and within canopy source height is estimated using the approach proposed by Shuttleworth and Gurney (1990)

$$
\begin{aligned}
r_{\mathrm{as}}= & \frac{h \exp (\alpha)}{\alpha K_{\mathrm{h}}}\left[\exp \left(-\frac{\alpha z_{0_{\mathrm{s}}}}{h}\right)\right. \\
& \left.-\exp \left(-\frac{\alpha\left(z_{0}+d\right)}{h}\right)\right]
\end{aligned}
$$

where

$$
K_{\mathrm{h}}=K u^{*}(h-d)
$$

The bulk boundary layer resistance to heat and water vapor in the canopy, is computed following Choudhury and Monteith (1988)

$r_{\mathrm{ac}}=\frac{100 \alpha^{\prime}}{2\left(\mathrm{LAI}_{\text {green }}+\mathrm{LAI}_{\mathrm{dry}}\right)} \sqrt{\frac{W}{u_{\mathrm{h}}}} \frac{1}{1-\mathrm{e}^{-\alpha^{\prime} / 2}}$

The soil resistance to evaporation is an empirical resistance whose parameters are calibrated based on the bare soil observations during SUDMED field experiment. The exponential formulation of Passerat de Silans (1986) is used

$r_{\mathrm{ss}}=\exp \left(A-B \times \frac{w_{\mathrm{s}}}{w_{\mathrm{fc}}}\right)$

where $A$ and $B$ are calibrated empirical coefficients determined to be $A=11[\ln (s / m)]$ and $B=11[\ln (s / m)]$ for the study site.

The bulk stomatal resistance $r_{\mathrm{sc}}$, follows the classical Jarvis (1976) representation (as in Choudhury and Idso (1985)). Green and dry LAI are distinguished. They respectively appears as $\mathrm{LAI}_{\text {green }}$ from $\mathrm{LAI}_{\text {dry }}$ in this resistance expression. Plant transpiration is only regulated by the green part of the plant that is photosynthetically active. Thus the stomatal resistance

is taken to be

$$
\begin{aligned}
r_{\mathrm{sc}}= & \frac{r_{\mathrm{sc}, \text { min }}}{\mathrm{LAI}_{\text {green }}} f_{1}\left(S_{\downarrow}\right) f_{2}\left(w_{2}\right) f_{3}\left(e^{*}\left(T_{\mathrm{a}}\right)-e_{\mathrm{a}}\right) \\
& f_{4}\left(T_{\mathrm{c}}-T_{\mathrm{a}}\right)(\mathrm{A} 27)
\end{aligned}
$$

where $f_{1}\left(S_{\downarrow}\right)$ is a stress function related to the solar incoming radiation

$$
\begin{aligned}
f_{1}\left(S_{\downarrow}\right) & =\frac{1+f}{f+\left(r_{\mathrm{s}, \min } / r_{\mathrm{s}, \min }\right)}, \quad \text { where } \quad f \\
& =0.011 \frac{2 S_{\downarrow}}{\mathrm{LAI}_{\text {green }}}
\end{aligned}
$$

The water stress is expressed as in Noilhan and Planton (1989)

$$
f_{2}\left(w_{2}\right)= \begin{cases}1_{w_{\mathrm{fc}}}-w_{\text {wilt }} & \text { when } w_{2}>w_{\mathrm{fc}} \\ \hline w_{2}-w_{\text {wilt }} & \text { when } w_{\mathrm{fc}} \geq w_{2} \geq w_{\text {wilt }} \\ +\infty & \text { when } w_{2}<w_{\text {wilt }}\end{cases}
$$

The water vapor stress factor depends on the vapor pressure deficit

$$
f_{3}\left(e^{*}\left(T_{\mathrm{a}}\right)-e_{\mathrm{a}}\right)=\frac{1}{1-D_{\mathrm{P}}\left(e^{*}\left(T_{\mathrm{a}}\right)-e_{\mathrm{a}}\right)}
$$

The temperature stress factor depends on the canopy and air temperature difference

$$
f_{4}\left(T_{\mathrm{c}}-T_{\mathrm{a}}\right)=\frac{1}{1-D_{\mathrm{T}}\left(T_{\mathrm{c}}-T_{\mathrm{a}}\right)^{2}}
$$

Calibrations at the study site resulted in minimum stomatal resistance $\mathrm{rs}_{\min }=90 \mathrm{~s} \mathrm{~m}^{-1}$, vapor pressure deficit coefficient $D_{\mathrm{P}}=1.5 \mathrm{~Pa}^{-1}$ and temperature stress coefficient $D_{\mathrm{T}}=1.5\left[\mathrm{~K}^{-2}\right]$.

\section{Appendix B. List of variables and their units}

$B$

$c$

$c_{\mathrm{p}}$

$D$

$e^{*}(T)$

$e_{\mathrm{a}}$ slope of the retention curve depending on the soil characteristics-exponent relating soil matric potential to soil moisture content soil heat capacity $\left(\mathrm{J} \mathrm{m}^{-3} \mathrm{~K}^{-1}\right)$ Specific heat of air at constant pressure $\left(1012 \mathrm{~J} \mathrm{~kg}^{-1} \mathrm{~K}^{-1}\right)$

Isothermal vapor conductivity $\left(\mathrm{kg} \mathrm{m}^{-2} \mathrm{~s}^{-1}\right)$

Saturated vapor pressure at temperature $T$ (m bar) vapor pressure at above canopy reference height ( $\mathrm{m}$ bar) 
$e_{0}$

$g$

G

$h$

$H_{\mathrm{c}}, H_{\mathrm{s}}, H$

$k$

$k_{\mathrm{T}}$

K

$L_{\downarrow}$

\section{LAI \\ $\mathrm{LAI}_{\text {dry }}$ \\ $\mathrm{LAI}_{\text {green }}$ \\ $P$}

$r_{\mathrm{a}}$

$r_{\mathrm{ac}}$

$r_{\text {as }}$

$r_{\mathrm{sc}}$

$r_{\mathrm{ss}}$

$r_{\mathrm{s}, \min }$

Rnc, Rns, Rn

$S_{\downarrow}$

$T_{\mathrm{a}}$

$T_{\mathrm{c}}$

$T_{\mathrm{s}}$

$T_{0}$

$T_{2}$

$u_{\mathrm{a}}$

$u_{\mathrm{h}}$

$u_{0}$ vapor pressure at within canopy source height ( $\mathrm{m}$ bar)

gravity acceleration $\left(9.81 \mathrm{~m} \mathrm{~s}^{-2}\right)$

ground heat flux $\left(\mathrm{W} \mathrm{m}^{-2}\right)$

vegetation height $(\mathrm{m})$

sensible heat fluxes respectively above the canopy, from the bare soil and from the ground $\left(\mathrm{W} \mathrm{m}^{-2}\right)$

hydraulic conductivity $\left(\mathrm{m} \mathrm{s}^{-1}\right)$

soil thermal conductivity ( $\mathrm{W} \mathrm{K}^{-1} \mathrm{~m}^{-2}$ )

Von Karman's constant (0.4)

longwave incoming solar flux at the top of the canopy $\left(\mathrm{W} \mathrm{m}^{-2}\right)$

leaf area index

dry leaf area index

green leaf area index

precipitation reaching the soil per unit $\left(\mathrm{mm} \mathrm{s}^{-1}\right)$

aerodynamic resistance between within canopy source height and above canopy reference height $\left(\mathrm{s} \mathrm{m}^{-1}\right)$

aerodynamic resistance between canopy and within canopy source height $\left(\mathrm{s} \mathrm{m}^{-1}\right)$

aerodynamic resistance between ground surface and within canopy source height $\left(\mathrm{s} \mathrm{m}^{-1}\right)$

bulk stomatal resistance of the canopy (s m${ }^{-1}$ )

surface resistance of the ground to evaporation $\left(\mathrm{s} \mathrm{m}^{-1}\right)$

minimum stomatal resistance

$\left(50 \mathrm{~s} \mathrm{~m}^{-1}\right.$ for wheat and $150 \mathrm{~s} \mathrm{~m}^{-1}$ for olive trees)

net radiation respectively above the canopy, from the bare soil and from the ground $\left(\mathrm{W} \mathrm{m}^{-2}\right)$

shortwave incoming solar flux at the top of the canopy $\left(\mathrm{W} \mathrm{m}^{-2}\right)$

temperature of the air above the canopy at the reference height $(\mathrm{K})$

mean temperature of the canopy $(\mathrm{K})$

soil surface temperature $(\mathrm{K})$

mean air temperature at within canopy source height $(\mathrm{K})$

mean temperature of the soil in the root zone ( $\mathrm{K}$ )

wind speed at reference level $z_{\text {ref }}$ $\left(\mathrm{m} \mathrm{s}^{-1}\right)$

wind speed at top of the canopy: height $\mathrm{h}\left(\mathrm{m} \mathrm{s}^{-1}\right)$

wind speed at source height $\left(\mathrm{m} \mathrm{s}^{-1}\right)$

$\begin{array}{ll}u^{*} & \text { friction velocity }\left(\mathrm{m} \mathrm{s}^{-1}\right) \\ w_{\mathrm{fc}} & \text { volumetric soil moisture content at } \\ & \text { field capacity } \\ w_{\mathrm{s}} & \text { volumetric surface water content } \\ w_{\mathrm{sat}} & \text { volumetric soil moisture content } \\ & \text { saturation } \\ w_{\text {wilt }} & \text { volumetric soil moisture content at } \\ & \text { wilting point } \\ w_{2} & \text { mean volumetric soil moisture content } \\ & \text { in the root zone } \\ W & \text { characteristic leaf width }(\mathrm{m})\end{array}$

\section{Greek letters}

$\alpha_{\mathrm{c}} \quad$ canopy albedo $(0.22)$

$\alpha_{\mathrm{s}} \quad$ bare soil albedo $(0.20)$

$\gamma \quad$ psychrometric

constant

$\varepsilon_{\mathrm{c}} \quad$ canopy emissivity $(0.98)$

$\varepsilon_{\mathrm{s}} \quad$ bare soil emissivity $(0.96)$

$\lambda$ latent heat of vaporisation at the triple point $T_{\mathrm{t}}=273.16 \mathrm{~K}\left(2.45 \mathrm{E}+6 \mathrm{~J} \mathrm{~kg}^{-1}\right)$

$\lambda E_{\mathrm{c}}, \lambda E_{\mathrm{s}}, \lambda E$ latent heat fluxes respectively above the canopy, from the bare soil and from the ground $\left(\mathrm{W} \mathrm{m}^{-2}\right)$

$\rho$
$\rho_{\mathrm{w}}$
$\sigma$
$\psi_{2}$
$\psi_{\mathrm{f}}$
$\psi_{\mathrm{fc}}$
$\psi_{\text {sat }}$
$\psi_{\text {wilt }}$

density of air $\left(1.2 \mathrm{~kg} \mathrm{~m}^{-3}\right)$

density of water $\left(1000 \mathrm{~kg} \mathrm{~m}^{-3}\right)$

Stefan-Boltzmann
$\left(5.6705 \mathrm{E}-8 \mathrm{~W} \mathrm{~m}^{-2} \mathrm{~K}^{-4}\right)$

constant

soil water potential in the root zone (m) water foliar potential (m)

soil water potential at field capacity depending on soil characteristics (m) soil water potential at saturation depending on soil characteristics (m) soil water potential at wilting point depending on soil characteristics (m)

\section{References}

Boone A., 2002. Description du Schéma explicite du sol: ISBA-DIF (ISBA-DIFfusion). CNRM-Météo-France, Internal note, July.

Boulet, G., Chehbouni, A., Braud, I., 1999. Mosaic versus dual source approaches for modelling the surface energy balance of a semiarid land. Hydrol. Earth Syst. Sci. 3 (2), 247-258.

Brooks, R.H., Corey, A.T., 1966. Properties of porous media affecting fluid flow. J. Irrig. Drain. Div. Am. Soc. Civil Eng. 92 (IR2), 6188.

Brutsaert, W., 1982. Evaporation Into the Atmosphere, in: Reidel, D. (Ed.), Hingham, Mass, 299 pp.

Caparrini, F., Castelli, F., Entekhabi, D., 2004a. Estimation of surface turbulent fluxes through assimilation of radiometric surface temperature sequences. J. Hydrometeorol. 5 (1), 145-159. 
Caparrini F., Castelli F., Entekhabi D., 2004. Variational estimation of soil and vegetation turbulent transfer and heat flux parameters from sequences of multisensor imagery. Water Resour. Res. 40 (12) Paper No. 10.1029/2004WR003358.

Choudhury, B.J., Idso, S.B., 1985. An empirical model for stomatal resistance of field-grown wheat. Agric. Forest Meteorol. 36, 65-82.

Choudhury, B.J., Monteith, J.L., 1988. A four-layer model for the heat budget of homogeneous land surfaces. Royal Meteorol. Soc., Quarter. J. 114, 373-398.

Clothier, B.E., Clawson, K.L., Pinter Jr., P.J., Moran, M.S., Reginato, R.J., Jackson, R.D., 1986. Estimation of soil heat flux from net radiation during the growth of alfalfa. Agric. Forest Meteorol. 37, 319-329.

Crago, R., Brutsaert, W., 1996. Daytime evaporation and the selfpreservation of the evaporative fraction and the Bowen ratio. J. Hydrol. 178 (1-4), 241-255.

Crago, R., 1996. Conservation and variability of the evaporative fraction during the daytime. J. Hydrol. 180 (1-4), 173-194.

De Vries, D.A., 1958. Simultaneous transfer of heat and moisture in porous media. Eos, Trans. Amer. Geophys. Union. 39 (5), 909-916.

Duchemin, B., Hadria, R., Erraki, S., Boulet, G., Maisongrande, P., Chehbouni, A., Escadafal, R., Ezzahar, J., Hoedjes, J.C.B., Kharrou, M.H., Khabba, S., Mougenot, B., Olioso, A., Rodriguez, J.-C., Simonneaux, V., 2006. Monitoring wheat phenology and irrigation in Central Morocco: on the use of relationships between evapotranspiration, crops coefficients, leaf area index and remotelysensed vegetation indices. Agric. Water Manage. 79 (1), 1-27.

Fuchs, M., Hadas, A., 1972. The heat flux density in a nonhomogeneous bare loessial soil. Bound.-Lay. Meteorol. 3, 191-200.

Idso, J., Aase, K., Jackson, R.D., 1975. Net radiation-soil heat flux relations as influenced by soil water content variations. Bound.Lay. Meteorol. 9, 113-122.

Jarvis, P.G., 1976. The interpretation of leaf water potential and stomatal conductance found in canopies in the field. Phil. Trans. R. Soc. London, Ser. B. 273, 593-610.

Kustas, W.P., Daughtry, C.S.T., 1990. Estimation of the soil heat flux/ net radiation ratio from spectral data. Agric. Forest Meteorol. 49, 205-233.

Lhomme, J.P., Elguero, E., 1999. Examination of evaporative fraction diurnal behaviour using a soil-vegetation model coupled with a mixed-layer model. Hydrol. Earth Syst. Sci. 3 (2), 259-270.

Nichols, W.E., Cuenca, R.H., 1993. Evaluation of the evaporative fraction for parameterization of the surface, energy-balance. Water Resour. Res. 29 (11), 3681-3690.

Noilhan, J., Planton, S., 1989. A simple parameterization of land surface processes for meteorological models. Mon. Weather Rev. 117, 536-549.

Paulson, C.A., 1970. The mathematical representation of wind speed and temperature profiles in the unstable atmospheric surface layer. J. Appl. Meteor. 9, 857-861.

Passerat de Silans, A., 1986. Transferts de masse et de chaleur dans un sol stratifié soumis à une excitation atmosphérique naturelle. Comparaison modèle expérience. Thèse de l'institut National Polytechnique de Grenoble, France, 205 pp.

Santanello, J.A., Friedl, M.A., 2003. Diurnal covariation in soil heat flux and net radiation. J. Appl. Meteorol. 42 (6), 851-862.

Shuttleworth, W.J., Wallace, J.S., 1985. Evaporation from sparse crops - an energy combination theory. Quart. J. Royal Meteorol. Soc. 111, 839-855.

Shuttleworth, W.J., Gurney, R.J., Hsu, A.Y., Ormsby, J.P., 1989. FIFE: the variation in energy partition at surface flux sites. IAHS Publ. 1989. 186, 67-74.
Shuttleworth, W.J., Gurney, R.J., 1990. The theoretical relationship between foliage temperature and canopy resistance in sparse crops. Quart. J. Royal Meteorol. Soc. 116, 497-519.

Taconet, O., Bernard, R., Vidalmadjar, D., 1986a. Evapotranspiration over an agricultural region using a surface flux temperature model based on NOAA AVHRR data. J. Clim. Appl. Meteorol. 25 (3), 284-307.

Taconet, O., Carlson, T., Bernard, R., 1986b. Evaluation of a surface vegetation parameterization using satellite measurements of surface temperature. J. Clim. Appl. Meteorol. 25 (11), 1752-1767.

\section{Further reading}

Bastiaanssen, W.G.M., Pelgrum, H., Droogers, P., 1997. Area-average estimates of evaporation, wetness indicators and top soil moisture during two golden days in EFEDA. Agric. Forest Meteorol. 87 (23), 119-137.

Bastiaanssen, W.G.M., Menenti, M., Feddes, R.A., 1998a. A remote sensing surface energy balance algorithm for land (SEBAL) 1. Formulation. J. Hydrol. 213 (1-4), 198-212.

Bastiaanssen, W.G.M., Pelgrum, H., Wang, J., 1998b. A remote sensing surface energy balance algorithm for land (SEBAL) 2. Validation. J. Hydrol. 213 (1-4), 213-229.

Bastiaanssen, W.G.M., Noordman, E.J.M., Pelgrum, H., 2005. SEBAL model with remotely sensed data to improve waterresources management under actual field conditions. J. Irrigat. Drainage Eng. ASCE. 131 (1), 85-93.

Betts, A.K., Viterbo, P., Wood, E., 1998. Surface energy and water balance for the Arkansas Red River basin from the ECMWF reanalysis. J. Clim. 11 (11), 2881-2897.

Boni, G., Castelli, F., Entekhabi, D., 2000. Sampling strategies and assimilation of ground temperature for the estimation of surface energy balance components. IEEE Trans. Geosci. Remote Sens. 39, 165-172.

Boni, G., Entekhabi, D., Castelli, F., 2001. Land data assimilation with satellite measurements for the estimation of surface energy balance components and surface control on evaporation. Water Resour. Res. 37, 1713-1722.

Brutsaert, W., 1975. On a derivable formula for long-wave radiation from clear skies. Water Resour. Res. 11 (5), 742-744.

Campbell, G.S., 1974. A simple method for determining unsaturated conductivity from moisture retention data. Soil Sci. 117, 311-314.

Castelli, F., Entekhabi, D., Caporali, E., 1999. Estimation of surface heat flux and an index of soil moisture using adjoint-state surface energy balance. Water Resour. Res. 35 (10), 3115-3125.

Caparrini, F., Castelli, F., Entekhabi, D., 2003. Mapping of landatmosphere heat fluxes and surface parameters with remote sensing data. Bound.-Lay. Meteorol. 107 (3), 605-633.

Crago, R., 1986. Comparison of the evaporative fraction and the Priestley-Taylor alpha for parameterizing daytime evaporation. Water Resour. Res. 32 (5), 1403-1409.

Deardorff, J.W., 1978. Efficient prediction of ground surface temperature and moisture with inclusion of a layer of vegetation. J. Geophys. Res. 83 (C4), 1887-1903.

Dunne, S., Entekhabi, D., 2006. Land surface state and flux estimation using the ensemble Kalman smoother during the Southern Great Plains 1997 field experiment. Water Resour. Res. 42 (1), W01407, doi:10.1029/2005WR004334.

Gilles, R.R., Cui, J., Carlson, T.N., Kustas, W.P., Humes, K.S., 1997. Verification of the "triangle" method for obtaining surface soil water content and energy fluxes from remote measurements of 
NDVI and surface radiant temperature. Int. J. Remote Sens. 18, 3145-3166.

Jarvis, P.G., 1975. Water transfer in plants. In: de Vries, D.A., Afgan, N.G. (Eds.), Heat and Mass Transfer in the Plant Environment. Scripta, Washington, DC, pp. 369-394.

LoSeen, D., Chehbouni, A., Njoku, E., 1997. An approach to couple vegetation functioning and soil-vegetation-atmosphere-transfer models for semiarid grasslands during the HAPEX-Sahel experiment. Agric. Forest Meteorol. 83 (1-2), 49-74.

Ma, Y., Su, Z., Li, Z.-L., Koike, T., Menenti, M., 2002. Determination of regional net radiation and soil heat flux over a heterogeneous landscape of the Tibetan Plateau. Hydrol. Process. 16 (15), 29632971.

Moran, M.S., Clarke, T.R., Inoue, Y., Vidal, A., 1994. Estimating crop water deficit using the relation between surface-air temperature and spectral vegetation index. Remote Sens Environ. 49, 246-263.
Mecikalski, J.R., Diak, G.R., Anderson, M.C., Norman, J.M., 1999. Estimating fluxes on continental scales using remotely-sensed data in an atmospheric-land exchange model. J. Appl. Meteorol. 35, 1352-1369.

Monteith, J.L., 1981. Evaporation and surface temperature. Quart. J. R. Meteorol. Soc. 107, 1-27.

Pellenq, J., Boulet, G., 2004. A methodology to test the pertinence of remote-sensing data assimilation into vegetation models for water and energy exchange at the land surface. Agronomie 24, 197-204, doi:10.1051/agro:2004017.

Reichle, R., McLaughlin, D., Entekhabi, D., 2002. Hydrologic data assimilation with the ensemble Kalman filter. Mon. Weather Rev. 130 (1), 103-114.

Shuttleworth, W.J., 1991. Evaporation models in hydrology. In: Schmugge, T.J., André, J. (Eds.), Land Surface Evaporation. Springer, New York, pp. 93-120. 